the écraseur-I have seen yield excellent results in the hands of Mr. Erichsen. In Mr. Holt's practice, also, I have seen excellent results from the employment of the écraseur in a somewhat different manner-viz., by dividing the sublingual tissues horizontally with an écraseur, so as to allow the tongue to be drawn thoroughly forward, after which the instrument can be readily made to encircle the organ at its base. I wish now to place on record a case of removal of a great part of the tongue, affected with disease which involved also the floor of the mouth, by dividing the jaw after the manner of Mr. Syme, and then applying the écraseura proceeding for which, however, I can claim no originality, as I find it has been performed by Mr. Moore and Mr. Nunn at the Middlesex Hospital, and probably by other surgeons. The cases which cannot be treated without the severe complication of dividing the lower jaw are comparatively few, but where the disease has already involved the floor of the mouth, so that it is impossible to encircle the whole of it with the écraseur, or even to draw the tongue forward, no other proceeding can be adopted. Any or all of these operations appear to me, however, only applicable to cases of disease requiring the removal of the whole breadth of the organ; when but one side is involved, the écraseur, however applied, appears to me unsatisfactory, and I have myself obtained, and witnessed in the practice of others, much more satisfactory results from free excision with the knife, and the application of the actual cautery for the axrest of hrmorrhage. The following are the notes of my patient's case :-

L. D- aged sixty, was admitted into University College Hospital under my care on the 7 th September, 1868, suffering from cancer of the tongue, which had been noticed for six months. On looking into the mouth there was, between the tongue and the lower jaw on the left side, a ragged ulcerated surface occupying the floor of the mouth. This was prolonged to the side of the tongue, and with the finger a hard mass could be felt in the smbstance of the organ, extending heyond the median line and to about two inches from the tip. The patient complained of constant pain in the tongue, but was otherwise in good health. On Sept. 14th a slight enlargement of one of the submaxillary glands was to be felt. The operation had been deferred till the 19th, on account of the patient's private affairs.

On Sept. 19th, under chloroform, I divided the lower lip in the median line, and, having dissected back the tissues from the bone, bored a hole on each side below the level of the teeth, and then divided the jaw with a fine saw, keeping strictlo to the median line, so as to avoid extracting any teeth. The jaw being divided, the incision was prolonged to the hyoid bone, and, the halves of the jaw being retracted, the disease was dissected up from the floor of the mouth, and some of the sublingual structures were divided. A thread being passed through the tip of the tongue, it was drawn forward, and an écraseur was slipped over it and behind the disease in the substance of the tongne. The écraseur was worked at half-minute intervals, and the tongue divided. As soon as the division was completed, one of the ranine arteries was seen bleeding, and was effectually twisted. No more bleeding occurring, the wound was sponged out with solution of chloride of zinc (forty grains to an ounce), and the sides of the jaw were brought together with a piece of thick wire, which was twisted firmly. The lip was then brought together with two harelip pins and a suture, the lower part of the wound being left open for a drain. Two hours after the operation there was free bleeding from the mouth, and, as I had been called out of town, my colleague, Mr. Berkeley Hill, was sent for, who opened the wound and the jaw, when the ranine artery opposite to that twisted at the operation was found bleeding, and a ligature was applied to it and to another vessel, the parts being brought together as before.

No further hæmorrhage occurred, and the patient made an uninterruptedly good recovery, being liberally fed with an ordinary feeding-boat. The harelip pins were removed on the fourth day; and there being some submaxillary swelling, a poultice was applied for a few days. There was profuse discharge from the lower portion of the wound for three weeks; and no doubt much of this was saliva. After this time the discharge came from the mouth, a grood deal being caused by the irritation of the wire in the jaw, the ends of which came against the lower lip.

On the 17th of October (four weeks after the operation) the jaw not having united, I made an attempt to twist the wire tighter, since the patient felt the two pieces working upon one another. The ends of the wire, however, broke short off, and the attempt was necessarily abandoned. Under these circumstances, Mr. Ibbetson was applied to to fit a cap to the teeth to hold the pieces of the jaw firmly together. A model was taken by Mr. Ibbetson on the 21st of October; and on the following day an accurately-fitting cap of black vulcanite was put on, and was quite comfortable. On Oct. 28 th two small pieces of bone had worked. out from the symphysis. The saliva still flowed out of the mouth in great quantities. The tongue had quite healed; but the patient occasionally felt a darting pain in it. The patient had to wear the vulcanite cap for six weeks before the jaw was completely consolidated; and I then ventured to remove the wire, which up to that time had remained in the bone. He then returned to the country, the only complaint being an occasional overflow of saliva from the mouth.

It will be observed that the long stay of the patient in the hospital was entirely due to the non-union of the divided jaw; and I understand that in the cases of the same opetion at the Middlesex Hospital a similar difficulty was experienced. In the account of Mr. Syme's only successful case of removal of the entire tongue (ThE LancrT, Feb. 4th, 1865) by division of the jaw, and removal with the knife, no mention is made of the union of the bone; but it could hardly have been complete at the time of the patient's departure from Edinburgh. In my own case the greater age of the patient may account for the delayed union. The disease in the tongue presented the appearance of medullary rather than of epithelial cancer; and this opinion was confirmed by the committee of the Pathological Society to whom the preparation was referred.

Cavendish-place, January, 1869.

\section{ON SMALL-POX AND VACCINATIION IN INDIA.}

By ROBERT PRINGLE, M.D.,

SORGEON H.M.'S BENGAX, ARMY, AND SUPERINTENDFNT OF VACCINATION, NORTH-WEST PROVINCES OP INDIA.

(Coneluded from page 45.)

B. The prophylactic measures had recourse to by the Government of India, and comprehended in their schemes of vaccination.-These might be summed up in two systems-viz.:

1st. Vaccination carried on by the medical officers in charge of civil stations; and

2nd. That conducted by a class of medical officers specially selected, and relieved from all military and civil duties, to enable them to devote their whole attention to the subject.

1st. By medical officers in charge of civil stations. This system will require but a brief notice, as it is now abolished as such. The defects witnessed in it were guarded against in the second, the chief one being want of supervision, owing to the inability of the medical officers to leave their stations, and test theaccuracy of theirvaccinator's returns, his knowledge of his duties, or the character of his operations. 2nd. By medical officers specially selected for superintending vaccination. This is the system now adopted throughout India generally, and may be divided into two kinds - viz., that employed in the Bombay Presidency, where there is no general superintendence other than that of the Deputy Inspector-General of Hospitals of the Division, which, as far as I can learn, is limited to the receipt of the returns; and that in practice in the Bengal Presidency, where there are Divisional SuperintendentsGeneral of Vaccination, whose chief duty is to supervise their superintendents of vaccination. Being most conversant with the latter method, as carried on in the Northwest Provinces, and known as Dr. Pearson's Scheme, I will confine myself to a description of it, remarking in passing that his has the merit of being the original one in its most important details. In these details it will challenge a comparison with any other in practice in India; while its late 
universal adoption in the Bengal Presidency may be considered a proof of its superiority. To Dr. Pearson undoubtedly belong the entire credit and honour of having, after years of close attention to the subject, finally succeeded in establishing a voluntary system of vaccination as nearly approaching perfection as its machinery, so to speak, will admit of, while it is absolutely such in that of being self-supporting. By this latter remark I mean, the vaccine vesicle, once started, need never be lost, and this in a country where vaccination in the plains can be carried on beneficially for barely five out of the twelve months. How it is kept up during the remaining seven months, in quantities suffcient to admit of the vaccine vesicle being started afresh in a thousand places at once if necessary, I will show hereafter. It must not be forgotten that Dr. Pearson's scheme was conducted to its successful issue in the face of an opposition from the priest-ridden and caste-prejudiced natives of the North-west Provinces of India, which, should it have been advisable, would have called for a Vaccination Act similar to that found necessary in this country. I say if advisable, for I do not think such necessary, being clearly of opinion that the best basis for a system of vaccination in India is a voluntary one; but then the scheme must be carried out systematically and carefully-in short, in such a manner that its present and ultimate benefits will be selfevident to the natives; then I have no doubt of its voluntary universal adoption. Time must be allowed for this happy termination in the plains of India, but its extension on the present principles is all that is necessary, and if the publication of this paper leads to that happy result, I shall be amply rewarded. Liberal as the Government pecuniary grants have lately been, more money is needed to extend the scheme; and if millions laid out in works of irrigation will directly benefit the natives of India, thousands spent in vaccination will add to the population which will enjoy these benefits, by reducing in India the prevalence of smallpox and the fearful mortality from it, of both of which I have attempted to convey some idea. The mortality returns of the North-west Provinces, which I have had an opportunity of perusing, give, for reasons obvious to anyone who has studied the subject, but an imperfect estimate of the appalling mortality from small-pox, and I think it would be difficult to name any more fertile source of the allowed decrease in the population than is to be found in the prevalence of a disease acknowledged to be preventable.

The following are the main features of Dr. Pearson's scheme:-

1st. Supervision by European medical officers specially qualified for the work.

2nd. A carefully trained staff of native vaccinators.

3rd. Fixing the field of each vaccinator's operations within such limits as would admit of the benefits of systematic vaccination being made apparent in the district in which he works, whence the practice may be expected to spread on its own merits (the best foundation in a voluntary scheme like that under notice) to the surrounding districts.

4th. A system of returns so compiled as in their execution not to interfere with a given amount of work to be done, but yet capable in themselves of detecting any attempt at falsification.

To illustrate the preceding, I will briefly describe the duties of a superintendent of vaccination in the North-west Provinces, who is always a European medical officer. During the vaccinating season the superintendent's sole duty is to be marching through his district inspecting the operations of his native vaccinators, which he does in the following manner. Having arrived at the head-quarters of a vaccinator, by means of the vaccinator's diary he can readily ascertain how the work is progressing. On examining this diary, he takes a day's work and sends the vaccinator on to the village; and, having noted at random others where he has operated, he can, on arriving at any of them, by means of the "Village Numinal Return" left with the head man of the village by the vaccinator, call up the vaccinated cases. Thus the superintendent has the opportunity of testing the quality of the operations and the accuracy of the recorded results, when, should there be any attempt at falsification, it is not only readily detected, but done in such a manner that the vaccinator stands convicted on his own written evidence, every record being in his own handwriting. The knowledge which the vaccinators have that any attempt at falsi- fying returns will be soon found out, and the removal of any undue pressure as regards quantity in place of quality of operations being expected, have the best possible effect in keeping these returns correct. The vaccinator not being present during these random visits, the superintendent has ample opportunity of extracting from the villagers the estimate which they have formed of the vaccinator and his work, -an invaluable point in a voluntary system of vaccination, as on the bearing and conduct of these vaccinators rests much of the success or failure of the scheme. As the superintendent pays these visits on horseback, he will probably arrive at the particular village, if at any distance, as soon as the vaccinator; when, with the cases before the operator, he inspects them, and points out anything worthy of remark. At first sight it may appear that $I$ have entered too minutely into what might seem trifling details; but among a suspicious and bigoted population it is only by attention to these minutiæ that the former is allayed and the latter overcome; and when this is attained, careful and systematic vaccination has a foundation that nothing will shake. If there is one point more than another which I strive to impress on $\mathrm{my}$ native vaccinators, it is that one carelessly vaccinated case will produce an amount of injury to their reputation as vaccinators which fifty successful cases may not entirely remove; and that the records of their work which they leave in the villages will, if it is carelessly done, prove a powerful instrument against their future operations, by shaking the faith of the villagers in them personally, and their work generally. On the other hand, that they can wish for no better certificate of their skill as operators, and of the true benefits of vaccination, than the village return of a series of carefully vaccinated cases. To every ten or twelve of these native vaccinators is a native superintendent, who has been promoted for his zeal and good work. His duties consist chiefly in supervising the vaccinators while operating, aiding the superintendent in testing the accuracy of the returns and the quality of the work, and, should any opposition to the scheme arise in a district or village, using his personal influence to overcome it by explaining the benefits which may be expected from the adoption of vaccination; and it is astonishing what patience and tact they display, and how rare it is that they are not rewarded with success. The duties of the Superintendent-General are summed up in his title, while, speaking generally, his extensive knowledge of the subject, from the care and attention he has devoted to it, is of the greatest value to superintendents on joining the Vaccine Department, and not unfrequently to those who have been some years in it. This, to do the subject justice, is, as briefly as I can describe it, Dr. Pearson's scheme, though there are still many interesting details into which I have not time to enter. I trust, however, that I have said enough to show the authorities, and my professional brethren in this country, that a voluntary scheme of vaccination has to be gently handled in a country like India, if any ultimate benefit is to be derived from it.

I will now describe how the supply of vaccine lymph is kept up fresh and active in a country like India, where, owing to the heat of the plains of Hindoostan, the vaccine vesicle degenerates, and operations have to be closed. For this purpose I will take the system as I originated it in the tract of the Himalayan range of my division of superintendence, but must, in justice to Dr. Pearson, add, that it was taken from that previously practised by him.

With the exception of the tracts of India which are directly affected by the sea breezes, and those above an altitude of 6000 feet, the vaccine vesicle cannot be kept up in that country throughout the year in the perfect state in which it should be, either to impart its full benefit to the case operated on, or be the means of extending it to others. In the Doab (or, I may repeat, the country lying between the Ganges and Jumnah, and south of the Sewalick Range) the vaccine vesicle will not rise satisfactorily, as a rule, before the beginning of November, and deteriorates, becoming thus useless, towards the end of March, when all operations consequently cease. The vaccine lymph, however, before this degeneration sets in, can be taken in capillary tubes to the Himalayas, where, at first, at an altitude of 6000 feet, it can be kept in an active condition; but the altitude must be raised as the heat increases, till, at 8000 or 9000 feet, it is beyond the reach of climatic changes, and is propagated with the greatest facility. To enable me to keep up a con- 
stant supply of vaccine lymph I have divided my Himalayan tract into three districts, for reasons which I will give hereafter, and the operations are carried on as follows:-Owing to the paucity of the inhabitants at these high altitudes the operations, which are commenced in May, are limited at first to once a week ; but, as November draws near, when a large supply of vaccine lymph is required for the commencement of the vaccinating season in the plains (where it has to be started de novo), they are increased to twice, and if the number of cases will admit of it, to three times a week. After a sufficient number of uninjured vesicles have been left to impart full protection to the case, and enough lymph been taken to carry on vaccination in the village or neighbourhood, that which remains and is superfluous (an increased number of applications being primarily made with this object) is stored in capillary tubes by the vaccinators, who are specially instructed in this branch. At the close of the vaccinating season in the hills this supply is sent to the plains by the ordinary post, in time to commence operations in November simultaneously at forty or fifty centres in my divisions, and in sufficient quantities to meet all the demands made at my office for fresh vaccine lymph from the civil and military officers in my divisions. This method of propagating the vaccine vesicle is capable of being carried on indefinitely by the following simple expedient; and when once a vaccinator has obtained a characteristic vaccine vesicle, he must be very ignorant of his duties if, with the population of the plains, he applies again for lymph during that season. The expedient alluded to is applicable only to the Himalayas, owing, as I said before, to the scantiness of the population, where, as in my division, for instance, if all the cases requiring vaccination were operated on successfully in one season, there would not be a sufficient supply in the next to do aught else than merely keep up vaccination, without being able to store up an adequate supply for the plains season. To obviate this, I may repeat that I have divided my Himalayan district into three, and use one in a season, thus allowing fresh cases to collect in sufficient numbers during the next two, or if necessary, three years. It might be advanced against this plan that it unnecessarily exposes a population to the risks of small-pox. This, however, is fortunately not the case, as, owing to the very limited intercourse which these remote and high villages enjoy, with inoculation prohibited, small-pox will grow, but rarely enter them; and should such a contingency occur, with the few cases amenable to it, the vaccinator working in the villages below this high altitude could rapidly protect them by vaccination. I may here mention that the results of my first season in one of these Himalayan districts were nearly 500 good crusts and 200 well filled capillary tubes, a supply more than ample for my own wants, or the requisitions for vaccine lymph on my office.

I may briefly allude here, for the benefit of my professional brethren engaged in vaccination in this country, to the manner in which the vaccine operations are conducted in the North-west Provinces of India. Owing to the objection the natives have to allowing their children to be taken from one village to another, "arm-to-arm" vaccination is not had recourse to, except in the village itself. The vaccine lymph is conveyed for short distances and time on ivory points; when both are longer, in vaccine crusts; and when still longer, and the weather is becoming hotter, in capillary tubes. Without doubt the capillary tubes, as supplied by Dr. Husband, of Edinburgh, when filled and closed by skilful hands, are vastly superior to any other method for conveying or storing lymph, and, with the single exception of arm-to-arm vaccination, the most satisfactory method of vaccination; but, owing to the expense it would entail in the operations in the North-west Provinces, it is too costly to be generally adopted; and, fortunately, vaccine lymph on ivory points, when fresh and the weather is cool, is almost equally successful. I would merely add, that the vaccine needle, a slight modification of Dr. Graham Weir's, is the instrument employed in the vaccine operations of the North-west Provinces, in preference to the lancet; and, when skilfully applied with the light touch of a trained native vaccinator, most successful.

In a country where a Vaccination Act is in force, it is difficult to convey an idea of the opposition which has to be met and overcome before a voluntary system of vaccination, such as I have described, can be successfully carried on in a country like India. Every conceivable objection is started; but it was reserved for the priest-ridden and bigoted city of Benares to advance one which, for ingenuity, surpasses any I have ever heard. It was the following:- Some of the priests of this city (among whom are many deservedly respected for their learning) gave out that there was an old prophecy, that a black child would be born with white blood, who should rule India, and turn the English out, as they expressed it; and it was with a view to find out the advent of this child that the Government had given orders to scratch the arms of their children. The answer to this would be simply that the presence of blood during the operation, instead of being a proof of the vaccinator's skill, was the reverse; and that if in their neighbourhood any vaccinator was in the habit of doing so, his practice would soon be put a stop to. I could cite other objections, and, absurd and untenable as they undoubtedly are, it is surprising what credence the ignorant and priest-led Hindoo attaches to them, and how difficult it often is, from their very absurdity, to argue them out of their belief in them.

Years must elapse before the fearful scourge of small-pox can be even much abated in the plains of India, since, as I said before, vaccination is still in its infancy among the almost countless thousands of Hindoostan; and though it has a satisfactory footing in some considerable tracts of country, yet I should be painting the picture in too bright colours if $I$ did not add that there still are places in which it is struggling for a bare existence, and many more where its benefits are even unheard of. Careful and systematic vaccination must nevertheless win the battle over prejudice and apathy in the end; and it is impossible to suppose that the benefits witnessed in some districts by its adoption will fail to spread, by rumour at least, to others less favoured. There are districts in the Himalayas, such as those of Kumaon and Ghurwal, where Dr. $P$ arson has been at work for years, and where at last the benefits of vaccination have become self-evident to the natives by the almost complete absence now of small-pox. No doubt these districts, by their limited population and intercourse with the plains and with each other, present conditions more favourable to this happy result than the densely crowded villages of the plains, each of which might be considered a thoroughfare when compared with those in the Himalayas. Before long, I trust, my Himalayan district will be similarly freed from small-pox, and the natives preserved from the possibility of the recurrence of an epidemic like that which produced what I have before described, and termed a gap in the population.

In summing up the vast importance of this subject, I would beg to add that, after a continuous residence of nearly thirteen years in India, and having seen cholera in its most fatal haunts during three years at Juggernauth, and witnessed the effects of famine, I have arrived at the conclusion that, though the former may count its victims by hundreds, and the latter by larger numbers though at longer periods, yet both pale before the spectre of smallpox, stalking yearly through densely crowded villages, and seizing its victims from the children born since its last visit, with a mortality which it is appalling to contemplate; and, knowing this as I do, I confess to feeling an earnest desire to do all that in me lies to check a scourge allowed to be preventable. I return in January to my duties; but if, during my short stay in this country, I have succeeded in enlisting on the side of vaccination one tithe of the sympathy and help which the subject demands, I feel I shall not have pleaded in vain for the infant population of Hindoostan.

The Veto of Relieving Ofricers. - The Poor-law Board has given a decision adverse to Dr. Fitzpatrick, the medical officer of the West Derby Union, on the disputed point whether or not the relieving officer was justified in refusing to supply certain "extras" ordered by him to be given to one of the union patients. The Poor-law Board, however, points out that " the recommendation of a medical offeer as regards the supply of 'extras' is entitled to great weight, and it is not expedient it should be disregarded by the guardians, unless it appear that what is ordered is improper in its nature or excessive in quantity, or that the person on whose account it is ordered is in a position to provide it at his own cost." 